\title{
A multicenter, non-randomized, phase II study of docetaxel and carboplatin administered every 3 weeks as second line chemotherapy in patients with first relapse of platinum sensitive epithelial ovarian, peritoneal or fallopian tube cancer
}

Yun Wang ${ }^{1}$, Jørn Herrstedt2,3, Hanne Havsteen ${ }^{3}$, Rene DePoint Christensen ${ }^{4}$, Mansoor Raza Mirza², Bente Lund ${ }^{5}$, Johanna Maenpaa ${ }^{6}$ and Gunnar Kristensen ${ }^{1,7^{*}}$

\begin{abstract}
Background: In patients with ovarian cancer relapsing at least 6 months after end of primary treatment, the addition of paclitaxel to platinum treatment has been shown to improve survival but at the cost of significant neuropathy. In the first line setting, the carboplatin-docetaxel combination was as effective as the combination of carboplatin and paclitaxel but with less neurotoxicity. This study was initiated to evaluate the feasibility of carboplatin with docetaxel as second line treatment in patients with ovarian, peritoneal or fallopian tube cancer.

Methods: Patients with stage IC-IV epithelial ovarian, peritoneal or fallopian tube cancer were enrolled at the first relapse after at least 6 months since completion of the first line treatment. Docetaxel $75 \mathrm{mg} / \mathrm{m}^{2}$ was given as an one hour IV infusion followed immediately by carboplatin $(A \cup C=5)$ given as a 30-60 min. IV infusion on day 1 and repeated every 3 weeks for 6-9 courses. Primary endpoint was toxicity; secondary endpoints were response rate and the time to progression.

Results: A total of 74 patients were included. Of these, 50 patients received 6 or more cycles, 13 received 3-5 courses and 11 received less than 3 courses. A total of 398 cycles were given. Grade 3/4 neutropenia was seen in $80 \%$ (59 of 74) patients with an incidence of febrile neutropenia of 16\%. Grade 2/3 sensory peripheral neuropathy occurred in $7 \%$ of patients, but no grade 4 sensory peripheral neuropathy was observed. Sixty patients were evaluable for response. The overall response rate was $70 \%$ with $28 \%$ complete responses in the response evaluable patient population. Median progression-free survival was 12.4 months (95\% Cl 10.4-14.4).
\end{abstract}

Conclusions: The three-weekly regimen of docetaxel in combination with carboplatin was feasible and active as second-line treatment of platinum-sensitive ovarian, peritoneal and Fallopian tube cancer. The major toxicity was neutropenia, while the frequency of peripheral neuropathy was low.

Keywords: Phase II study, Recurrent platinum-sensitive ovarian cancer, Docetaxel, Carboplatin, Toxicity

\footnotetext{
* Correspondence: gunnar.b.kristensen@gmail.com

'Department of Gynecologic Oncology, Norwegian Radium Hospital, Oslo

University Hospital, PB 4953 Nydalen 0424, Oslo, Norway

'Department of Gynecologic Oncology and Institute for Medical Informatics,

Norwegian Radium Hospital, Oslo University Hospital, Oslo, Norway

Full list of author information is available at the end of the article
} 


\section{Background}

Epithelial ovarian cancer, the second most common gynecological malignancy, is the fifth leading cause of cancer-related death in women in the United States [1]. Most patients present with disease in advanced stage. Surgery followed by chemotherapy with carboplatin and paclitaxel has become the standard treatment [2]. Although most patients achieve a complete response, the majority will suffer a relapse and eventually die from the disease. Relapses occurring $\geq 6$ months after end of first line treatment are considered platinum sensitive and are advised to be treated with a platinum based regimen [3].

The ICON4/AGO-Ovar-2.2 study [4] demonstrated improved survival by adding paclitaxel to a platinum agent in patients with platinum sensitive recurrent ovarian cancer. However, this combination is associated with significant neurotoxicity [5]. Furthermore, many women will suffer from persistent neuropathy from the initial taxane containing regimen, making re-treatment with paclitaxel a difficult endeavor [6]. Studies have shown that patients report motor neuropathy as the most unpleasant adverse effect of treatment [7] and the development of neuropathy is a major factor impairing quality of life [8], which can lead to early treatment discontinuation.

The combination of carboplatin and docetaxel was found to be associated with similar survival as the combination of carboplatin and paclitaxel in first line treatment of ovarian cancer [9]. The combination of carboplatin and docetaxel caused considerably less neurotoxicity than carboplatinpaclitaxel with grade $\geq 2$ neurosensory toxicity in $11 \%$ versus $30 \%$ and grade $\geq 2$ neuromotor toxicity in $3 \%$ versus $7 \%$ of patients. The positive clinical experiences with carboplatin plus docetaxel provide a strong basis for continued investigation of platinum/docetaxel based chemotherapy in the management of advanced ovarian cancer.

Only a few studies have evaluated docetaxel in combination with carboplatin as second-line combination chemotherapy for ovarian cancer [10,11]. A phase II trial of docetaxel and carboplatin in recurrent platinumsensitive ovarian, peritoneal or Fallopian tube cancer with a platinum-free interval of at least 6 months [10] enrolled 25 patients. Docetaxel $75 \mathrm{mg} / \mathrm{m}^{2}$ followed by carboplatin (AUC5) on day 1 was given every 3 weeks for 6 courses. Among the 23 evaluable patients, the overall response rate was $72 \%$ with $16(64 \%)$ complete and $2(8 \%)$ partial responses. Sensory neuropathy grade $1 / 2$ was observed in 10 patients $(40 \%)$, no grade $3 / 4$ sensory or motor neuropathy was observed. Neutropenia was the most frequent grade 3/4 hematologic toxicity occurring in 15 patients $(60 \%)$, but no episodes of febrile neutropenia was observed in this trial.

In order to evaluate the combination of carboplatin and docetaxel as treatment of platinum-sensitive recurrent ovarian, peritoneal and Fallopian tube cancers, the Nordic Society of Gynecologic Oncology (NSGO) performed a phase II trial in patients with a relapse $\geq 6$ months after completion of first line treatment.

\section{Methods}

\section{Study patients}

Eligibility criteria included age $\geq 18$ years, a histologically verified diagnosis of epithelial ovarian carcinoma, peritoneal or Fallopian tube cancer and disease progression 6 months or later after completion of first line treatment with carboplatin and paclitaxel. Measurable disease according to Response Evaluation Criteria in Solid Tumors (RECIST 1.0) or CA-125 assessable disease according to Gynecologic Cancer Inter Group (GCIG) criteria [12,13]. Other key eligibility criteria included a WHO performance status of $0-2$ and adequate bone marrow, renal and hepatic function. Patients with pre-existing peripheral neuropathy (National Cancer Institute Common Toxicity Criteria for Adverse Events [NCI-CTCAE version 2] > grade 1) were excluded.

The study was designed and carried out in accordance with good clinical practice, the declaration of Helsinki and national laws. The local ethics committee at each participating center approved the study (Danmark: Den Videnskabsetiske komite or Vejle og Fyns Amter; Norway: Regional Committees For Medical and Health Research Studies; Finland: Regional ethical review board). All patients gave their written informed consent before study entry.

\section{Study design}

Patients were prospectively recruited into this single arm study. The main endpoint was toxicity, with special emphasis on the frequency of febrile neutropenia. Secondary endpoints were response rate and progression free survival. Treatment was given as a combination of docetaxel $75 \mathrm{mg} / \mathrm{m}^{2}$ intravenously followed by carboplatin $(\mathrm{AUC}=5)$ based on the Calvert formula [14] using the glomerular filtration rate calculated according to the method of Cockroft and Gault [15]. Treatment was repeated every 3 weeks for 6-9 cycles unless progressive disease or unacceptable toxicity occurred. Written informed consent in compliance with the recommendations of the Declaration of Helsinki was obtained in all cases before inclusion. The study was registered with ClinicalTrials.gov (NCT02026921).

\section{Treatment plan and dose modification}

All patients received premedication with corticosteroid and a serotonin receptor antagonist. With bone marrow recovery within 28 days, the patients were retreated with full dose of docetaxel. With recovery within 29-35 days, the dose of docetaxel was reduced to $60 \mathrm{mg} / \mathrm{m}^{2}$. When 
hematologic recovery was not achieved at day 35 , the patient went off study. Only one dose reduction of docetaxel was allowed. In case of febrile neutropenia $\left(\mathrm{ANC}<1 \times 10^{9} / \mathrm{L}\right.$ and fever $\left.\geq 38.5^{\circ} \mathrm{C}\right)$ the dose of docetaxel was reduced to $60 \mathrm{mg} / \mathrm{m}^{2}$ and the dose of carboplatin to AUC4 in the subsequent cycles. Use of granulocyte colony stimulating factor (G-CSF) was not allowed on a routine basis, but could be used at the discretion of the investigator in case of myelotoxicity.

In case of peripheral neuropathy or oedema (grade 2) or gastrointestinal toxicity (diarrhoea, nausea, and vomiting grade 3) treatment was delayed until recovery for a maximum of 2 weeks and patients were retreated with docetaxel $60 \mathrm{mg} / \mathrm{m}^{2}$. In case of grade $3 / 4$ peripheral neuropathy (motor or sensory), oedema grade $3 / 4$ or any non-hematological toxicity grade 4 , patients went off study.

\section{Clinical evaluation and assessments}

Baseline assessments were performed within 14 days prior to study entry and included: hematological tests (full blood count and differential white cell count); biochemical profile (CA125, total serum bilirubin, alkaline phosphatases, AST or ALT and creatinine); physical examination (WHO performance status, weight, and height); radiological examination including chest X-Ray, abdominal-pelvic CT-scan. Other radiological examinations as indicated.

During chemotherapy, hematological tests were performed before each infusion and again on day $14+/-2$ days. Biochemical tests and physical examination were performed before each infusion. Measurement of all lesions reported at baseline and screening for new lesions were performed every $9^{\text {th }}$ week with the same method as used at baseline. Evaluation of response was done according to RECIST 1.0 criteria. Adverse events were graded using NCI-CTCAE version 2.

Serious adverse events (SAEs) occurring within 30 days after chemotherapy were reported. Clinical follow-up was performed every 3 months for the first 2 years, every 6 months the following year and annually thereafter, respectively. Responses were verified at the first follow up visit when applicable. During follow-up, CA125 was measured at each visit until progression. All patients (including patients who were withdrawn from the protocol treatment) were followed according to this scheme.

\section{Statistical methods}

Progression-free survival was defined as time from registration to progression or death by any cause. Survival curves were determined using Kaplan-Meier estimates. The sample size was chosen to allow for a relative narrow confidence interval for the frequency of febrile neutropenia.

\section{Results}

Patient characteristics and treatments

A total of 74 patients were enrolled into this phase II trial by 6 member institutions of NSGO from August 2004 to August 2005. Patient demographics are outlined in Table 1. The median age was 61 years (range, 27-79 years). The majority of patients had ovarian cancer (93\%), FIGO stage III/IV disease (85\%), and 60 patients (81\%) had serous type histology. A total of 398 cycles

\section{Table 1 Demographics and tumor characteristics}

\begin{tabular}{|c|c|}
\hline Characteristics $(n=74)$ & No. of patients (\%) \\
\hline Age, median years (range) & $61(21-79)$ \\
\hline \multicolumn{2}{|l|}{ Primary site } \\
\hline Ovary & $69(93)$ \\
\hline Peritoneal & $2(3)$ \\
\hline Fallopian tube & $3(4)$ \\
\hline \multicolumn{2}{|l|}{ Original stage } \\
\hline lc & $5(7)$ \\
\hline$\| \mathrm{b}$ & $1(1)$ \\
\hline IIC & $5(7)$ \\
\hline IIla & $4(5)$ \\
\hline$\| l l b$ & $5(7)$ \\
\hline IIIC & $45(61)$ \\
\hline IV & $8(11)$ \\
\hline Unknown & $1(1)$ \\
\hline \multicolumn{2}{|l|}{ Tumor grade } \\
\hline Well differentiate & $11(15)$ \\
\hline Moderate well differentiate & $21(28)$ \\
\hline Poorly differentiate/undifferentiate & $36(49)$ \\
\hline Unknown & $6(8)$ \\
\hline \multicolumn{2}{|l|}{ Histologic type } \\
\hline Serous & $60(81)$ \\
\hline Mucinous & $2(3)$ \\
\hline Clear cell & $2(3)$ \\
\hline Endometroid & $5(7)$ \\
\hline Undifferentiate & $1(1)$ \\
\hline Other & $4(5)$ \\
\hline \multicolumn{2}{|l|}{ Response to firs line therapy } \\
\hline Complete response (CR) & $38(51)$ \\
\hline Partial response (PR) & $8(11)$ \\
\hline Stable disease (SD) & $2(3)$ \\
\hline Non-evaluated disease (NED) & $26(35)$ \\
\hline \multicolumn{2}{|l|}{$\begin{array}{l}\text { Time from end of first line } \\
\text { chemotherapy to relapse }\end{array}$} \\
\hline Median months (range) & $15.7(6-80.9)$ \\
\hline Relapse between 6 to 12 months & $26(35.1 \%)$ \\
\hline Relapse $>12$ months & $48(64.9 \%)$ \\
\hline
\end{tabular}


were given. Eleven patients received only 1-2 courses, 13 received $3-5$ courses and 50 received at least 6 courses. The reason for withdrawal before completion of the planned 6 cycles were progression in 4 patients, allergic reaction to carboplatin in 10 , allergic reaction to docetaxel in 1 , febrile neutropenia in 2 , impaired performance status in 1 , increased liver enzymes in 1 , other toxicities in 4 and withdrawal of consent in 1 patient. Of patients who received only 1-2 courses, 1 stopped due to early progression, 2 due to toxicity, 1 due to allergic reaction to docetaxel and 7 due to allergic reaction to carboplatin.

Dose reduction of docetaxel was done in 26 of 398 cycles (7\%, 14 patients) and dose reduction of carboplatin was done in 5 of 398 cycles (1\%, 4 patients). In total, dose reduction was done in 16 of 74 patients (22\%).

Cycle prolongation of up to one week occurred in 20 patients due to the following reasons: neutropenia 5 patients, neutropenia and thrombocytopenia 1 patient, reduced performance status 3 patients, increased liver enzymes 1 patient, oedema 1 patient, intercurrent disease 4 patients and logistic reasons 5 patients. One patient had a cycle prolongation of more than one week due to an intercurrent disease.

\section{Toxicity}

Non-hematologic toxicities of docetaxel-carboplatin are summarized in Table 2. Significant non-hematologic toxicities were uncommon, and overall the combination was

Table 2 Non-hematologic toxicity

\begin{tabular}{lcccc}
\hline & \multicolumn{4}{c}{ Grade of toxicity (NCI-CTVAE grade v2.0) } \\
\cline { 2 - 5 } & $\mathbf{1}$ & $\mathbf{2}$ & $\mathbf{3}$ & $\mathbf{4}$ \\
& $\mathbf{n}(\%)$ & $\mathbf{n}(\%)$ & $\mathbf{n}(\%)$ & $\mathbf{n}(\%)$ \\
\hline Arthralgia & $23(31)$ & $2(3)$ & $1(1)$ & $0(0)$ \\
Myalgia & $29(39)$ & $4(5)$ & $0(0)$ & $0(0)$ \\
Nausea & $36(49)$ & $12(16)$ & $4(5)$ & $0(0)$ \\
Vomiting & $9(12)$ & $7(9)$ & $4(5)$ & $0(0)$ \\
Mucositis/Stomatitis & $21(28)$ & $13(18)$ & $0(0)$ & $0(0)$ \\
Neurohearing & $3(4)$ & $1(1)$ & $0(0)$ & $0(0)$ \\
Neuromotor & $2(3)$ & $1(1)$ & $0(0)$ & $0(0)$ \\
Neurosensory & $34(46)$ & $4(5)$ & $1(1)$ & $0(0)$ \\
Edema & $13(18)$ & $4(5)$ & $0(0)$ & $0(0)$ \\
Fatigue & $24(32)$ & $18(24)$ & $0(0)$ & $0(0)$ \\
Change of taste & $13(18)$ & $4(5)$ & $0(0)$ & $0(0)$ \\
Anorexia/weight loss & $2(3)$ & $1(1)$ & $0(0)$ & $0(0)$ \\
Diarhoe & $6(8)$ & $0(0)$ & $0(0)$ & $0(0)$ \\
Nail changes & $6(8)$ & $5(7)$ & $0(0)$ & $0(0)$ \\
Rash & $2(3)$ & $1(1)$ & $0(0)$ & $0(0)$ \\
Epiphora & $1(1)$ & $2(3)$ & $0(0)$ & $0(0)$ \\
\hline NCl-CrCAE: Natona & (1) & &
\end{tabular}

NCl-CTCAE: National Cancer Institute Common Toxicity Criteria for Adverse Events. well tolerated. Treatment-related sensory peripheral neuropathy was low, with grade 2 in 4 patients and grade 3 in 1 patient. Three patients (4\%) suffered grade $1 / 2$ motor peripheral neuropathy and none had grade $3 / 4$.

Nausea, arthralgia/myalgia, mucositis/stomatitis and fatigue were the most common non-hematologic toxicities, but rarely severe. Grade 3 emesis was reported in 4 patients (5\%) and grade 3 arthralgia in one patient (1\%). Grade 2 fatigue was reported in 18 patients (24\%). Edema was not a significant clinical problem. Increased fluid retention grade 2 that did not require diuretic therapy was reported by 4 patients $(5 \%)$.

Hematologic toxicity is presented in Table 3. Neutropenia and leukopenia were most frequently reported. The incidence of grade 3 and 4 neutropenia was $27 \%$ $(20 / 74)$ and 53\% (39/74), respectively. Febrile neutropenia was reported in 12 patients $(16 \%)$, in 5 of these in the first course and in 3 in the second or third course. In 6 patients (8\%) G-CSF was used after an episode of febrile neutropenia. Anemia was quite common but mild. Grade $1 / 2$ anemia occurred in 64 patients (86\%), no grade $3 / 4$ anemia was reported. Nine patients (12\%) received blood transfusion and 1 patient (1\%) received erythropoietin support. Thrombocytopenia was rare, with only 7 patients (9\%) experiencing this toxicity of whom 2 (3\%) had grade 4 .

\section{Response and survival}

Evaluation of response was performed in 61 patients with measurable disease. Seventeen achieved a complete response, 26 a partial response, 8 had stable disease and 10 had progression during treatment. The overall response rate was $70 \%(43 / 61)$ in the efficacy-evaluable patient population and $58 \%(43 / 74)$ in the intention to treat population. The median progression-free survival in the ITT population was 12.4 months (95\% CI 10.4-14.4) as shown in Figure 1.

\section{Discussion}

Overall the combination was well tolerated. Most cases of arthralgia and myalgia were mild. The most unpleasant side effects were mucositis/stomatitis grade 2 and fatigue

Table 3 Hematologic toxicity

\begin{tabular}{lcccc}
\hline & \multicolumn{4}{c}{ Grade of toxicity $($ NCI-CTVAE grade v2.0) } \\
\cline { 2 - 5 } & $\mathbf{1}$ & $\mathbf{2}$ & $\mathbf{3}$ & $\mathbf{4}$ \\
& $\mathbf{n}(\%)$ & $\mathbf{n}(\%)$ & $\mathbf{n}(\%)$ & $\mathbf{n}(\%)$ \\
\hline Leucocytopenia & $15(20)$ & $27(36)$ & $21(28)$ & $3(4)$ \\
Neutropenia & $3(4)$ & $5(7)$ & $20(27)$ & $39(53)$ \\
Febrile neutropenia & $0(0)$ & $0(0)$ & $12(16)$ & $0(0)$ \\
Thrombocytopenia & $4(5)$ & $1(1)$ & $0(0)$ & $2(3)$ \\
Anemia & $44(59)$ & $20(27)$ & $0(0)$ & $0(0)$ \\
\hline
\end{tabular}

NCI-CTCAE: National Institute Common Toxicity Criteria for Adverse Events. 


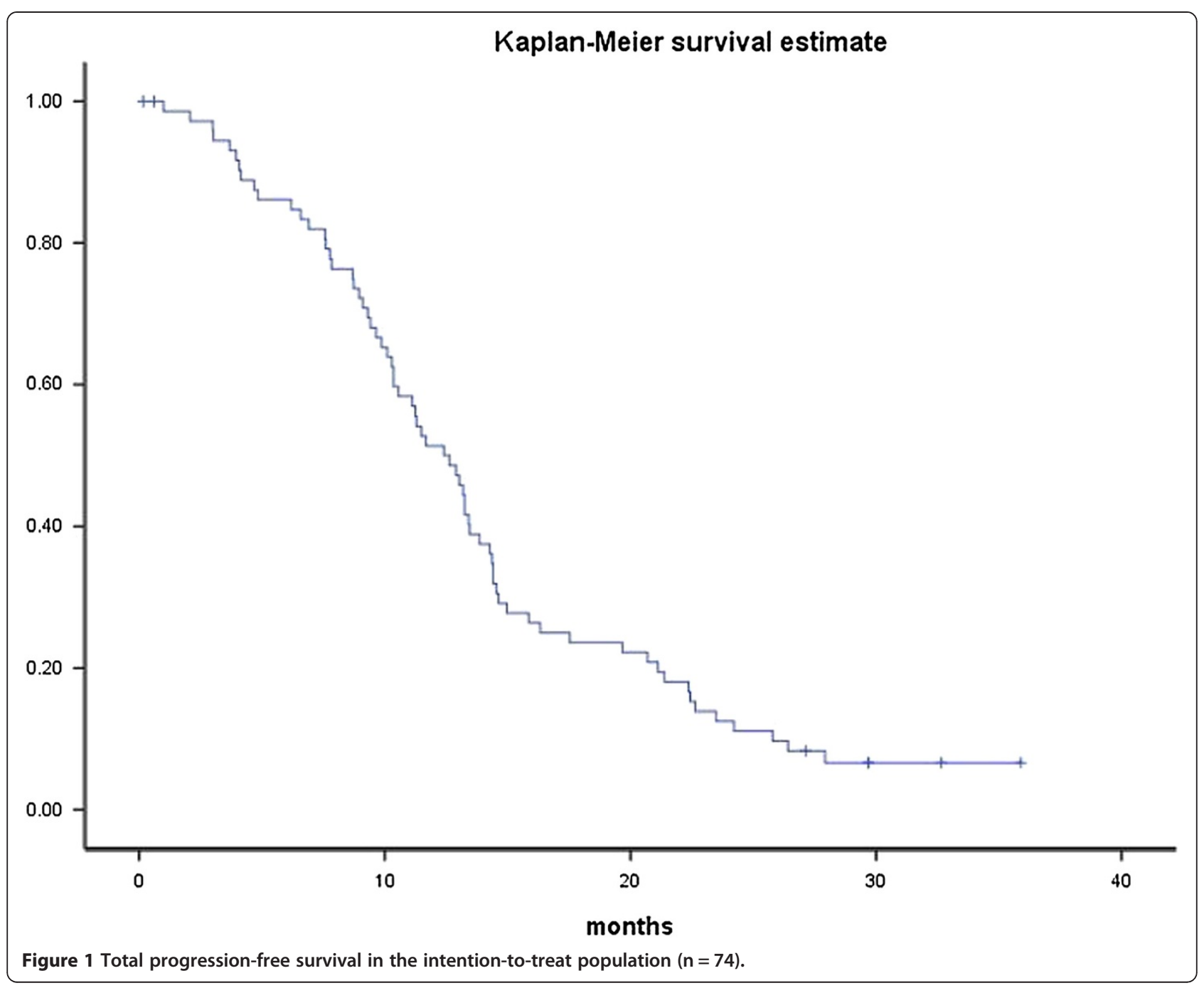

grade 2 , reported 18 and $24 \%$ of patients, respectively. The frequency of neurotoxicity was low. Neuropathy grade 2 and 3 was reported in only $6 \%$ and $1 \%$ of patients, respectively. This low frequency is in line with the findings in other studies on the combination of carboplatin and docetaxel in relapsed ovarian cancer $[10,16,17]$. In contrast, up to $27 \%$ moderate or severe neurological toxicity ( $\geq$ grade 2) has been observed in studies with the platinumpaclitaxel combination in recurrent ovarian, peritoneal and fallopian tube cancer $[4,18]$. The study was restricted to patients with a maximum of grade 1 neurotoxicity at recruitment, thus we cannot evaluated how this combination would influence on more pronounced preexisting neuropathy. Unlike neuropathy induced by paclitaxel, which may manifest early during treatment, docetaxelinduced neutropathy generally does not appear until cumulative dose of docetaxel exceeds $600 \mathrm{mg} / \mathrm{m}^{2}$ [17]. As docetaxel is associated with less neurotoxicity than paclitaxel and generally is delivered as a convenient 1-hour infusion, suitable for out-patient administration, it might be a good substitution for paclitaxel in order to decrease neuropathy in the treatment of recurrent ovarian cancer.

As anticipated, neutropenia was the major toxicity in the present study, occurring with grade $3 / 4$ in $80 \%$ of all patients and was the main reason for dose reductions. Previous studies have demonstrated a high incidence of severe (grade 3/4) neutropenia when combining docetaxel with carboplatin in the treatment of ovarian and other gynecologic malignancies. A range of $33.3 \%-94 \%$ has been reported in first line $[9,19,20]$, and of $60 \%-98 \%$ in second-line chemotherapy $[10,16]$.

Febrile neutropenia was reported in $11 \%$ of patients in the SCOTROC study [9] on first line chemotherapy. This did not compromise dose delivery or safety. In the present study, a higher frequency of febrile neutropenia (16\%) was observed as could be expected in the second line setting. Febrile neutropenia usually occurred early in the treatment. The frequency of febrile neutropenia seen in our and another study [18] call for prophylactic use of G-CSF support when this combination is used in 
second line. Guidelines recommend prophylactic use of G-CSF in older patients (> 65 years-old) and in those with comorbidities if the risk of febrile neutropenia exceeds $10 \%$ [21]. In accordance with other studies $[9,10,19]$, thrombocytopenia was infrequent and usually mild. We observed only two patients with thrombocytopenia grade 4 . The low rate of thrombocytopenia indicates that docetaxel may have a thrombocyte sparing effect when combined with paclitaxel.

In first line treatment of ovarian cancer, the combination of carboplatin and docetaxel has been found as effective as the carboplatin-paclitaxel combination [9]. Although inter-study comparisons are problematic, the findings of an overall response rate of $70 \%$ in the response evaluable population and a median progression free survival of 12.4 months in the present study are in line with the findings in studies using carboplatin in combination with either paclitaxel or pegylated liposomal doxorubicin in second line treatment of ovarian cancer $[4,18,22]$.

The relative high frequency of carboplatin hypersensitivity reactions is in accordance with previous reports $[16,18,23]$ on repeated treatment with carboplatin in patients with relapsed ovarian cancer. It is of interest that this frequency seemed to be lower when these women were treated with the combination of carboplatin and pegylated doxorubicin compared to carboplatin and paclitaxel [18].

\section{Conclusions}

The 3 weekly regimen of docetaxel in combination with carboplatin was feasible and active in second-line treatment for platinum-sensitive ovarian, peritoneal and fallopian tuber cancer with a low frequency of peripheral neuropathy. The major toxicity was neutropenia.

\section{Competing interests}

The authors declare that they have no competing interests.

\section{Authors' contributions}

YW prepared the manuscript. JH coordinated the trial in Denmark, contributed with data and reviewed and approved manuscript. $\mathrm{HH}$ contributed with data and approved the manuscript. RDPC performed the statistical analyses. MRM contributed with data and approved the manuscript. BL contributed with data and approved the manuscript. JM contributed with data and reviewed and approved the manuscript. GK planned and organised the trial and participated in preparing the manuscript. All authors read and approved the final manuscript.

\section{Acknowledgements}

The study was supported by a grant from Sanofi Aventis.

\section{Author details}

'Department of Gynecologic Oncology, Norwegian Radium Hospital, Oslo University Hospital, PB 4953 Nydalen 0424, Oslo, Norway. ${ }^{2}$ Department of Oncology, Odense University Hospital, Odense, Denmark. ${ }^{3}$ Department of Oncology, Herlev University Hospital, Herlev, Denmark. ${ }^{4}$ Research Unit of General Practice, Institute of Public Health, University of Southern Denmark, Odense, Denmark. 'Department of Oncology, Ålborg University Hospital, Ålborg, Denmark. 'Department of Obstetrics and Gynecology, School of Medicine, University and University Hospital of Tampere, Tampere, Finland. ${ }^{7}$ Department of Gynecologic Oncology and Institute for Medical Informatics, Norwegian Radium Hospital, Oslo University Hospital, Oslo, Norway.
Received: 13 May 2014 Accepted: 20 November 2014

Published: 11 December 2014

\section{References}

1. Jemal A, Siegel R, Xu J, Ward E: Cancer statistics, 2010. CA Cancer J Clin 2010, 60:277-300.

2. DuBois A, Quinn M, Thigpen T, Vermorken J, Vall-Lundqvist E, Bookman M, Bowtell D, Brady M, Casado A, Cervantes A, Eisenhauer E, Friedlaender M, Fujiwara K, Grenman S, Guastalla P, Harper P, Hogberg T, Kaye S, Kitchener H, Kristensen G, Mannel R, Meier W, Miller B, Neijt P, Oza A, Ozols R, Parmar M, Pecorelli S, Pfisterer J, Poveda A, et al: 2004 consensus statements on the management of ovarian cancer: final document of the 3rd International Gynecologic Cancer Intergroup Ovarian Cancer Consensus Conference (GCIG OCCC 2004). Ann Oncol 2005, 16(Suppl 8):viii7-viii12.

3. Pfisterer J, Ledermann JA: Management of platinum-sensitive recurrent ovarian cancer. Semin Oncol 2006, 33:S12-S16.

4. Parmar MK, Ledermann JA, Colombo N, Du BA, Delaloye JF, Kristensen GB, Wheeler S, Swart M, Qian W, Torri V, Floriani I, Jayson G, Lamont A, Trope C: Paclitaxel plus platinum-based chemotherapy versus conventional platinum-based chemotherapy in women with relapsed ovarian cancer: the ICON4/AGO-OVAR-2.2 trial. Lancet 2003, 361:2099-2106.

5. Ozols RF, Bundy BN, Greer BE, Fowler JM, Clarke-Pearson D, Burger RA, Manne RS, DeGeest K, Hartenbach EM, Baergen R: Phase III trial of carboplatin and paclitaxel compared with cisplatin and paclitaxel in patients with optimally resected stage III ovarian cancer: a Gynecologic Oncology Group study. J Clin Oncol 2003, 21:3194-3200.

6. Armstrong DK: Relapsed ovarian cancer: challenges and management strategies for a chronic disease. Oncologist 2002, 7(Suppl 5):20-28.

7. Dranitsaris G, Elia-Pacitti J, Cottrell W: Measuring treatment preferences and willingness to pay for docetaxel in advanced ovarian cancer. Pharmacoeconomics 2004, 22:375-387.

8. Roila F, Cortesi E: Quality of life as a primary end point in oncology. Ann Oncol 2001, 12(Suppl 3):S3-S6.

9. Vasey PA, Jayson GC, Gordon A, Gabra H, Coleman R, Atkinson R, Parkin D, Paul J, Hay A, Kaye SB: Phase III randomized trial of docetaxel-carboplatin versus paclitaxel-carboplatin as first-line chemotherapy for ovarian carcinoma. J Natl Cancer Inst 2004, 96:1682-1691.

10. Strauss HG, Henze A, Teichmann A, Karbe I, Baumgart A, Thomssen C, Koelbl $\mathrm{H}$ : Phase II trial of docetaxel and carboplatin in recurrent platinumsensitive ovarian, peritoneal and tubal cancer. Gynecol Oncol 2007, 104:612-616.

11. Kushner DM, Connor JP, Sanchez F, Volk M, Schink JC, Bailey HH, Harris LS, Stewart SL, Fine J, Hartenbach EM: Weekly docetaxel and carboplatin for recurrent ovarian and peritoneal cancer: a phase II trial. Gynecol Oncol 2007, 105:358-364.

12. Vergote I, Rustin GJ, Eisenhauer EA, Kristensen GB, Pujade-Lauraine E, Parmar MK, Friedlander M, Jakobsen A, Vermorken JB: Re: new guidelines to evaluate the response to treatment in solid tumors [ovarian cancer] Gynecologic Cancer Intergroup. J Natl Cancer Inst 2000, 92:1534-1535.

13. Therasse P, Arbuck SG, Eisenhauer EA, Wanders J, Kaplan RS, Rubinstein L, Verweij J, Van Glabbeke M, van Oosterom AT, Christian MC, Gwyther SG: New guidelines to evaluate the response to treatment in solid tumors. European Organization for Research and Treatment of Cancer, National Cancer Institute of the United States, National Cancer Institute of Canada. J Nat/ Cancer Inst 2000, 92:205-216.

14. Calvert AH, Newell DR, Gumbrell LA, O'Reilly S, Burnell M, Boxall FE, Siddik ZH, Judson IR, Gore ME, Wiltshaw E: Carboplatin dosage: prospective evaluation of a simple formula based on renal function. J Clin Oncol 1989, 7:1748-1756.

15. Cockcroft DW, Gault MH: Prediction of creatinine clearance from serum creatinine. Nephron 1976, 16:31-41.

16. Arimoto T, Nakagawa S, Oda K, Kawana K, Yasugi T, Taketani Y: Second-line chemotherapy with docetaxel and carboplatin in paclitaxel and platinum-pretreated ovarian, fallopian tube, and peritoneal cancer. Med Oncol 2012, 29:1253-1254.

17. Hilkens PH, Verweij J, Stoter G, Vecht CJ, van Putten WL, van den Bent MJ: Peripheral neurotoxicity induced by docetaxel. Neurology 1996, 46:104-108.

18. Pujade-Lauraine E, Wagner U, Avall-Lundqvist E, Gebski V, Heywood M, Vasey PA, Volgger B, Vergote I, Pignata S, Ferrero A, Sehouli J, Lortholary A, Kristensen G, Jackisch C, Joly F, Brown C, Le Fur N, Du Bois A: Pegylated liposomal Doxorubicin and Carboplatin compared with Paclitaxel and 
Carboplatin for patients with platinum-sensitive ovarian cancer in late relapse. J Clin Oncol 2010, 28:3323-3329.

19. Markman M, Kennedy A, Webster K, Peterson G, Kulp B, Belinson J: Combination chemotherapy with carboplatin and docetaxel in the treatment of cancers of the ovary and fallopian tube and primary carcinoma of the peritoneum. J Clin Oncol 2001, 19:1901-1905.

20. Pfisterer J, Du BA, Wagner U, Quaas J, Blohmer JU, Wallwiener D, Hilpert F: Docetaxel and carboplatin as first-line chemotherapy in patients with advanced gynecological tumors. A phase I/ll trial of the Arbeitsgemeinschaft Gynakologische Onkologie (AGO-OVAR) Ovarian Cancer Study Group. Gynecol Oncol 2004, 92:949-956.

21. Aapro MS, Bohlius J, Cameron DA, Dal LL, Donnelly JP, Kearney N, Lyman GH, Pettengell R, Tjan-Heijnen VC, Walewski J, Weber DC, Zielinski C: 2010 update of EORTC guidelines for the use of granulocyte-colony stimulating factor to reduce the incidence of chemotherapy-induced febrile neutropenia in adult patients with lymphoproliferative disorders and solid tumours. Eur J Cancer 2011, 47:8-32.

22. Pfisterer J, Vergote I, Du BA, Eisenhauer E: Combination therapy with gemcitabine and carboplatin in recurrent ovarian cancer. Int J Gynecol Cancer 2005, 15(Suppl 1):36-41.

23. Markman M, Kennedy A, Webster K, Elson P, Peterson G, Kulp B, Belinson J: Clinical features of hypersensitivity reactions to carboplatin. $J$ Clin Oncol 1999, 17:1141-1145.

doi:10.1186/1471-2407-14-937

Cite this article as: Wang et al:: A multicenter, non-randomized, phase II study of docetaxel and carboplatin administered every 3 weeks as second line chemotherapy in patients with first relapse of platinum sensitive epithelial ovarian, peritoneal or fallopian tube cancer. BMC Cancer 2014 14:937.

\section{Submit your next manuscript to BioMed Central and take full advantage of:}

- Convenient online submission

- Thorough peer review

- No space constraints or color figure charges

- Immediate publication on acceptance

- Inclusion in PubMed, CAS, Scopus and Google Scholar

- Research which is freely available for redistribution 